\title{
MICRO AND NANO ORGANIZATION OF ATMOSPHERIC PARTICULATE MATTER IN GRIGORESCU DISTRICT OF CLUJ-NAPOCA
}

\author{
IOAN PETEAN ${ }^{\mathrm{a}}$, GERTRUD ALEXANDRA PALTINEAN ${ }^{\mathrm{a} *}$, \\ AURORA MOCANU ${ }^{a}$, DANA FLORINA MUNTEAN ${ }^{b}$, LIANA MURESAN ${ }^{b}$, \\ GEORGE ARGHIR ${ }^{c}$, MARIA TOMOAIA-COTISEL ${ }^{a, d}$
}

\begin{abstract}
The paper is focused on the micro and nano organization of atmospheric particulate matter in Grigorescu district of Cluj-Napoca in April and May 2017. Floating particles (FP) collected from atmosphere have an increased amount of minerals such as: quartz, calcite, clays (e.g. kaolinite and muscovite), and traces of lepidocrocite. Their size varies from less than 1 to over $120 \mu \mathrm{m}$, established by Scherer method on an XRD pattern. PM10 contains mainly quartz and calcite followed by fractions of kaolinite and muscovite. PM2.5 contains clay in large amount and less quartz particles. Certain nanoparticles are found among PM2.5. The obtained values were in good agreement to TEM and AFM microscopy. The diameters are $42 \mathrm{~nm}$ for clay and $92 \mathrm{~nm}$ for quartz particles. Nanostructural features are organized around fine micro particles such as PM 2.5. PM10 is often found as particles around FP.
\end{abstract}

Keywords: floating particles, PM10, PM2.5, micro and nano organization

\section{INTRODUCTION}

The composition and distribution of particulate matter (PM) depend on the particularities of soil, weather, and human activities. Neglected and eroded soils lead to an increased amount of mineral particles in PM [1-4].

\footnotetext{
a Babeş-Bolyai University, Faculty of Chemistry and Chemical Engineering, Arany Janos Str., No. 11, RO-400084 Cluj-Napoca, Romania.

${ }^{b}$ Environmental Protection Agency Cluj, Dorobanţilor Str., No. 99, RO-400609, Cluj - Napoca, Romania.

c Technical University of Cluj - Napoca, Faculty of Materials and Environment Engineering, Muncii Ave., No. 103 -105, RO-400641 Cluj - Napoca, Romania.

${ }^{d}$ Academy of Romanian Scientists, 54 Splaiul Independentei, 050094, Bucharest, Romania

*Corresponding author: pgertrud@gmail.com
} 
Human activities, industrial and transport, lead to significant amount of anthropogenic PM such as acid falls, soot, and minerals resulted from industrial processes [5-9]. All these particles could be lifted into the atmosphere by weather conditions such as intense air currents related to dry environment. Humid weather as rainy days and snow during winter inhibit the spreading of particles into the atmosphere $[10,11]$. Recent studies evidenced nanoparticles among small fraction of PM such as PM2.5 $[12,13]$. Fine micro-particles and nanoparticles dispersed into the atmosphere present high risk of acute or chronic lung affections [14-16].

Grigorescu district of Cluj-Napoca is situated far away from industrial facilities and is affected only by residential activities and transport traffic. Thus, it is expected to found among PM fractions mainly particles derived from soil decay than particles resulted from anthropogenic sources.

\section{RESULTS AND DISCUSSION}

The first category of investigated PM was the floating particles (FP). These contain various particles lifted in atmosphere due to the weather condition. They fall back to the soil as sediment layer after their flight. XRD spectrum reveals FP sample composition, Figure $1 \mathrm{a}$.

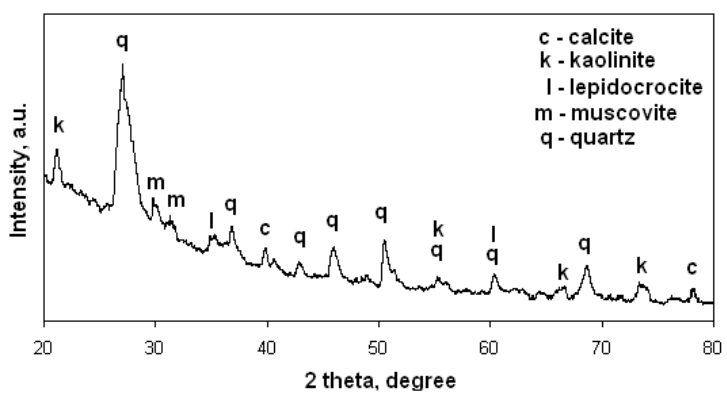

a

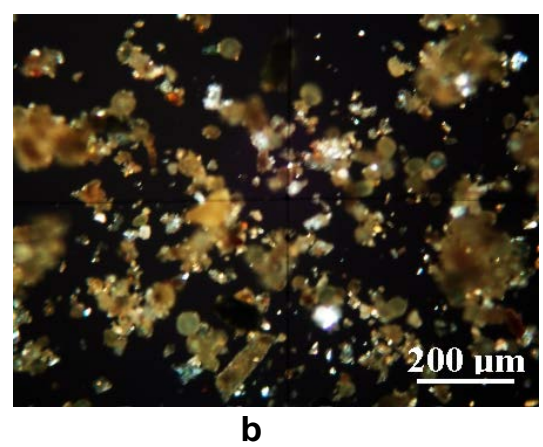

Figure 1. Mineralogical characterization of the FP sample collected from Grigorescu district with the Air Quality Monitoring Station: a) XRD pattern and b) cross polarized light microscopy image.

The dominant mineral is quartz, followed by calcite, clays (e.g. kaolinite, and muscovite), and traces of lepidocrocite. Cross polarized light microscopy, Figure $1 \mathrm{~b}$, allows determining the characteristics of particles from each mineral class data in Table 1. 
Table 1. Components properties of FP sample

\begin{tabular}{|c|c|c|c|c|c|}
\hline Component & Quartz & Kaolinite & Muscovite & Calcite & Lepidocrocite \\
\hline Formula & $\mathrm{SiO}_{2}$ & $\mathrm{Al}_{2} \mathrm{Si}_{2} \mathrm{O}_{5}(\mathrm{OH})_{4}$ & $\mathrm{KAl}_{2}\left(\mathrm{AlSi}_{3} \mathrm{O}_{10}\right)(\mathrm{F}, \mathrm{OH})_{2}$ & $\mathrm{CaCO}_{3}$ & $\mathrm{\gamma FeO}(\mathrm{OH})$ \\
\hline $\begin{array}{c}\text { Particle size, } \\
\mu \mathrm{m}\end{array}$ & $3-120$ & $1-30$ & $1-30$ & $5-100$ & $5-30$ \\
\hline Color & $\begin{array}{c}\text { Green - } \\
\text { gray }\end{array}$ & $\begin{array}{c}\text { White- } \\
\text { blue }\end{array}$ & Pink & $\begin{array}{c}\text { Yellow- } \\
\text { brown }\end{array}$ & $\begin{array}{c}\text { Reddish - } \\
\text { brown }\end{array}$ \\
\hline Shape & round & tabular & tabular & round & elongated \\
\hline
\end{tabular}

Data in Table 1 shows significant particle size ranges which match the category of PM10 and PM2.5. These PM fractions were monitorized by Automatic Air Quality Monitoring Station and representative samples were subjected to SEM imaging and SEM-EDX elemental analysis, Figure 2 and Table 2.

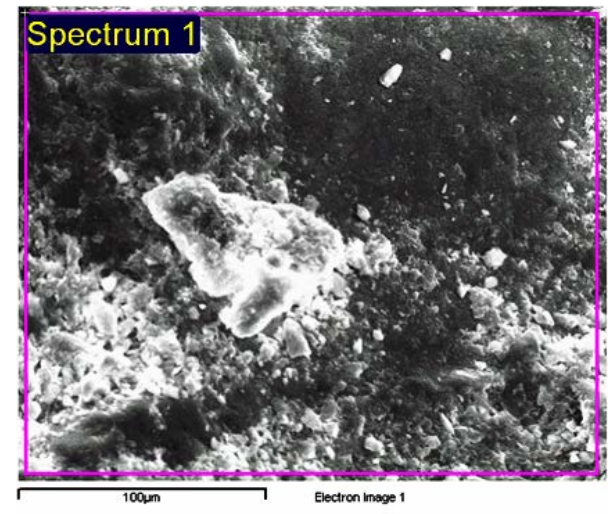

a

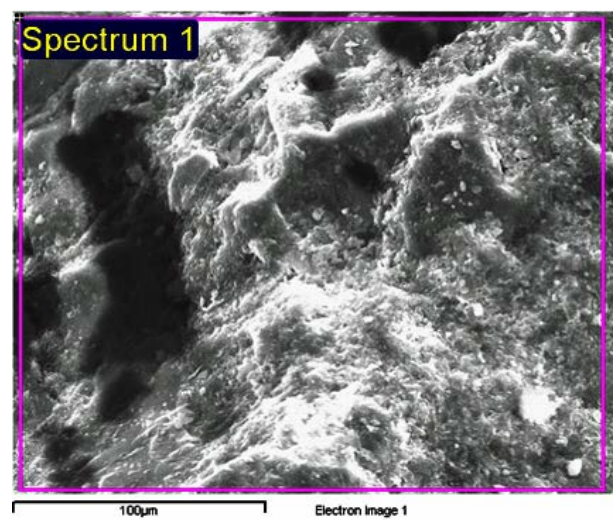

b

Figure 2. SEM images for particulate matters: a) PM10 and b) PM2.5.

PM10 sample, Figure $2 \mathrm{a}$, present a mixture of well individualized particles having diameters between 2.6-10 $\mu \mathrm{m}$ surrounding a particle conglomerate of $60 \mu \mathrm{m}$. The coalescence tendency is proven as observed in literature $[12,13,17]$. PM2.5 sample features a dense deposit of fine micro particle having diameters below $2.5 \mu \mathrm{m}$, Figure $2 \mathrm{~b}$. 
IOAN PETEAN, GERTRUD ALEXANDRA PALTINEAN, AURORA MOCANU, DANA FLORINA MUNTEAN, LIANA MURESAN, GEORGE ARGHIR, MARIA TOMOAIA-COTISEL

Table 2. Elemental composition for PM10 and PM2.5, EDX analysis.

\begin{tabular}{|c|c|c|c|c|}
\hline \multirow{2}{*}{ Element } & \multicolumn{2}{|c|}{ PM10 } & \multicolumn{2}{c|}{ PM2.5 } \\
\cline { 2 - 5 } & weight \% & atomic \% & weight \% & atomic \% \\
\hline $\mathrm{C}$ & 11.27 & 16.52 & 32.52 & 43.47 \\
\hline $\mathrm{O}$ & 59.40 & 65.37 & 42.53 & 42.67 \\
\hline $\mathrm{Na}$ & - & - & 2.09 & 1.46 \\
\hline $\mathrm{Mg}$ & 0.32 & 0.23 & 0.48 & 0.32 \\
\hline $\mathrm{Al}$ & 1.15 & 0.75 & 5.26 & 3.13 \\
\hline $\mathrm{Si}$ & 26.41 & 16.56 & 12.72 & 7.27 \\
\hline $\mathrm{S}$ & - & - & 0.41 & 0.20 \\
\hline $\mathrm{K}$ & 0.23 & 0.10 & 0.35 & 0.14 \\
\hline $\mathrm{Ca}$ & 0.68 & 0.30 & 2.59 & 1.04 \\
\hline $\mathrm{Fe}$ & 0.53 & 0.17 & 1.05 & 0.30 \\
\hline $\mathrm{Total}$ & 100.00 & 100.00 & 100.00 & 100.00 \\
\hline
\end{tabular}

The elemental composition for PM10 and PM2.5, given in Table 2, is in good agreement with XRD observation in Figure 1a and respectively in Figure $1 \mathrm{~b}$, all elements being specific to the identified minerals. Carbon is related to calcite and high amount of oxygen to large amount of silicate minerals. A trace of $0.41 \mathrm{wt}$. \% of sulphur is an exception for PM2.5. Elemental distribution reveals that PM10 is reach in quartz and PM2.5 is reach in clay particles such as kaolinite and muscovite. These are flat and have small diameter being able to form compact layers as observed in Figure $2 \mathrm{~b}$.

PM10 and PM2.5 emissions were daily monitored during April and May 2017, measurement being performed by the Automatic Air Quality Monitoring Station from Grigorescu district. The data are compiled in Table 3, where minimum, maximum, and average values are given. A pattern was observed: the weekends with relative high humidity feature the lowest PM emission and the dry days of the middle week leads to high value of emission. However, the recorded emissions are below the limit. Grigorescu district has a friendly environment for the lungs and it worth to live there. The limit of $40 \mu \mathrm{g} / \mathrm{m}^{3}$ was exceeded at PM10 only in a day per month where maximum values were recorded $46.59 \mu \mathrm{g} / \mathrm{m}^{3}$ and $39.16 \mu \mathrm{g} / \mathrm{m}^{3}$.

Table 3. PM emission level in Grigorescu district for April and May 2017

\begin{tabular}{|c|c|c|c|}
\hline \multicolumn{2}{|c|}{ Emission type } & April 2017 & May 2017 \\
\hline \multirow{2}{*}{$\begin{array}{c}\mathrm{PM} 2.5, \\
\mu \mathrm{g} / \mathrm{m}^{3}\end{array}$} & minim & 7.07 & 12.32 \\
\cline { 2 - 4 } & maxim & 24.65 & 23.75 \\
\hline \multirow{2}{*}{$\begin{array}{c}\mathrm{PM} 10, \\
\mu \mathrm{g} / \mathrm{m}^{3}\end{array}$} & minim & 11.45 & 18.05 \\
\cline { 2 - 4 } & maxim & 2.92 & 9.79 \\
\hline $\begin{array}{c}\mathrm{FP}, \\
\mathrm{g} / \mathrm{m}^{2} / \mathrm{mon}\end{array}$ & average & 46.59 & 39.16 \\
\hline
\end{tabular}


PM2.5 was dispersed in ultra-pure water, micro-particles sediment to the bottom of Berzelius glass beaker and the nanoparticles remains into dispersion. Liquid dispersed sample was subjected to TEM investigation. For XRD and AFM studies, the nanoparticles were deposited onto solid substrate (e.g. glass plate) by vertical adsorption according to the procedure [18 - 23].

XRD pattern, Figure $3 a$, shows less intense and broadened peaks than the ones resulted for FP sample, Figure 1 . This is the effect of reducing the particles size. The sample does not have internal tensions which might affect the peak broadening, then Scherer method is suitable for particle size determination [24]. The Scherer method was applied to kaolinite, muscovite, and quartz peaks. The results are centralized in Table 4.

TEM image, Figure $3 b$, shows bigger quartz nanoparticle having a diameter of about $90 \mathrm{~nm}$ and clay particles ranging from 40-45 nm diameter. It is a good agreement with XRD results.

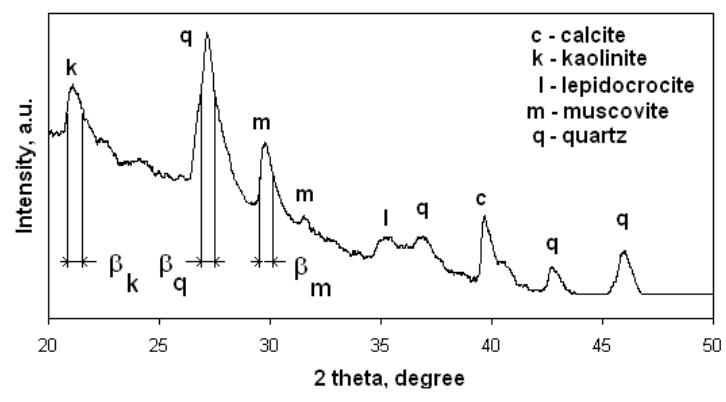

a

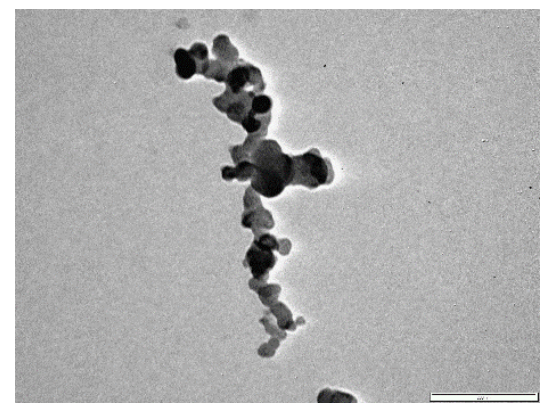

b

Figure 3. Characterization of PM2.5 thin layer from Grigorescu district collected with the Air Quality Monitoring Station:

a) XRD pattern and b) TEM microscopy, scale bar $200 \mathrm{~nm}$.

The AFM images presented in Figure 4, resulted for the thin film of nanoparticles, extracted from PM2.5 via aqueous dispersion. The topographic image shows a uniform nanoparticles film having a roughness of $1.38 \mathrm{~nm}$, Figure 4a. Nanoparticles are well individualized as observed in phase image, Figure $4 \mathrm{~b}$. The nanoparticles appear in light brown and the border between them in light yellow.

Several profiles were taken to establish the nanoparticle diameter. It results two categories of nanoparticles: fewer around $90 \mathrm{~nm}$ comparable with value obtained for quartz and many having around $40-45 \mathrm{~nm}$ as observed in cross section presented in Figure 4d. 


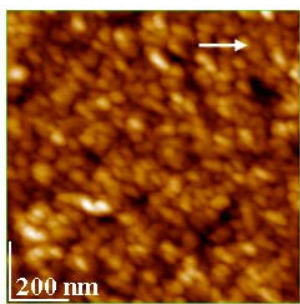

a

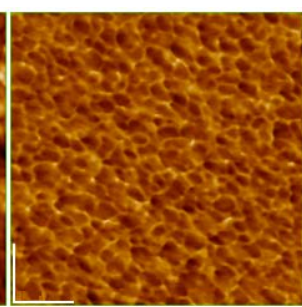

b

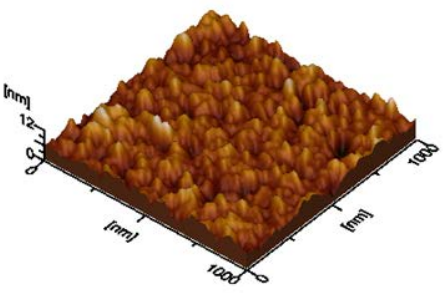

c

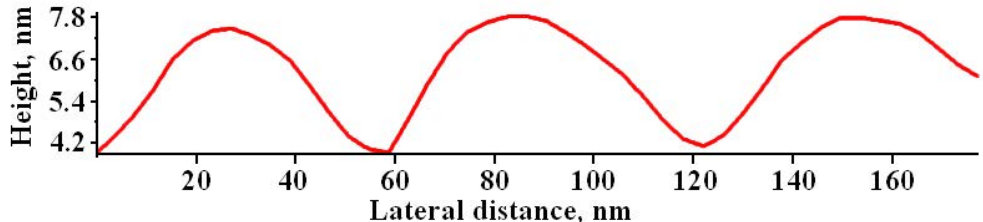

d

Figure 4. AFM images of PM2.5 thin layer from Grigorescu district collected with the Air Quality Monitoring Station: a) topographic image, b) phase image, c) 3D image, and d) profile along white arrow in figure (a).

Table 4. Nano-particles diameter by several measurement techniques

\begin{tabular}{|c|c|c|c|c|}
\hline \multirow{2}{*}{ Mineral } & \multicolumn{4}{|c|}{ Particle diameter, nm } \\
\cline { 2 - 5 } & AFM & TEM & XRD & $\begin{array}{c}\text { Rounded } \\
\text { value }\end{array}$ \\
\hline Kaolinite & $40 \pm 3$ & 40 & 45.77 & 42 \\
\hline Muscovite & $40 \pm 5$ & 45 & 41.32 & 42 \\
\hline Quartz & $90 \pm 6$ & 90 & 95.21 & 92 \\
\hline
\end{tabular}

All values obtained for nanoparticles size are centralized in Table 4. They are in good agreement for al used techniques, so we could establish a rounded value as a characteristic for each mineral involved. The clay nanoparticles are around $42 \mathrm{~nm}$ and quartz nano-particles around $92 \mathrm{~nm}$.

\section{CONCLUSIONS}

The particulate matter contains mineral composition of quartz, calcite, clays (e.g. kaolinite and muscovite), and traces of lepidocrocite in Grigoresu district, of Cluj-Napoca, during April and May 2017. Their size varies from less than 1 to over $120 \mu \mathrm{m}$. PM10 contains mainly quartz and calcite followed by 
fractions of kaolinite and muscovite. PM2.5 sample is abundant in clay particles and contains less quartz than PM10. Nanoparticles were found among PM2.5. XRD, TEM, and AFM allow establishing nanoparticles nature and size: kaolinite and muscovite $42 \mathrm{~nm}$ and quartz $92 \mathrm{~nm}$. Air monitoring during April and May 2017 in Grigoresu District, Cluj - Napoca, shows that emission level is under the limit.

\section{EXPERIMENTAL SECTION}

The experimental area is situated in Grigorescu district, of ClujNapoca. PM samples: FP, PM10, and PM2.5 were collected using Automatic Air Quality Monitoring Station CJ-3 from Environmental Protection Agency of Cluj-Napoca, and their level of emission in the atmosphere was monitored during April and May 2017 and the results were centralized.

The X-ray diffraction analysis was performed on a DRON 3 diffractometer equipped with data acquisition module and MATMEC VI.0 soft. A monochrome $\mathrm{CO}_{\mathrm{ka}}$ radiation was used for all X-ray spectra. The mineral identification was effectuated using MATCH $1.0 \mathrm{X}$ - ray standard data base from Crystal Impact Co.

Optical microscopy was performed on a Karl Zeiss Jena Laboval 2 microscope equipped with digital capture Kodak $10 \mathrm{Mpx}$ camera. Quantitative analysis on the optical microphotographs was done using the Image J professional soft as freeware resource from National Institutes of Health, USA.

The AFM investigation was performed on a Jeol JSPM 4210 microscope in tapping mode [25-32] using NSC 15 cantilever. Samples for AFM investigation were prepared according to the appropriate data [33-38]. AFM images and cross profile were processed into the standard manner using Win SPM 2.0 soft. SEM images were achieved on a Jeol JSM 5600 LV microscope in secondary electrons imaging mode.

\section{REFERENCES}

1. G.A. Hosu-Prack, I. Petean, G. Arghir, L.D. Bobos, M. Tomoaia-Cotisel, Studia Univ. Babes-Bolyai, Chemia, 2010, 55 (3), 93.

2. I. Petean, A. Mocanu, G. A. Paltinean, R. Tarcan, D. F. Muntean, L. Muresan, G. Arghir, M. Tomoaia-Cotisel, Studia Univ. Babes-Bolyai, Chemia, 2017, 62 (4), Tom I, 33. 
IOAN PETEAN, GERTRUD ALEXANDRA PALTINEAN, AURORA MOCANU, DANA FLORINA MUNTEAN, LIANA MURESAN, GEORGE ARGHIR, MARIA TOMOAIA-COTISEL

3. W. De Poel, S. Pintea, J. Drnec, F. Carla, R. Felici, P. Mulder, J. Elemans, W. Van Enckevort, A.E. Rowan, E. Vlieg, Surface Science, 2014, 619, 19.

4. M.S. Żbik, N.A. Raftery, R.S.C. Smart, R.L. Frost, Applied Clay Science, 2010, 50, 299.

5. G.A. Hosu-Prack, I. Petean, G. Arghir, L.D. Bobos, I. Iurcut, M. Tomoaia-Cotisel, Carpathian Journal of Earth and Environmental Sciences, 2013, 8 (4), 75.

6. J. Berger, B. Denby, Atmospheric Environment, 2011, 45, 3692.

7. M. Giugliano, G. Lonati, P. Butelli, L. Romele, R. Tardivo, M. Grosso, Atmospheric Environment, 2005, 39, 2421.

8. G. Lazar, C. Capatina, C.M. Simionescu, Revista de Chimie (Bucharest), 2014, 65 (10), 1215.

9. G. Damian, F. Damian, D. Năsui, C. Pop, C. Pricop, Carpathian Journal of Earth and Environmental Sciences, 2010, 5 (1),139.

10. D.F. Muntean, D. Ristoiu, G. Arghir, R.F. Campean, I. Petean, Carpathian Journal of Earth and Environmental Sciences, 2012, 7 (3), 175.

11. D.F. Muntean, I. Ivan, L. Muresan, Studia Univ. Babes-Bolyai, Chemia, 2015, 60 (2), 207.

12. G.A. Paltinean, I. Petean, G. Arghir, D.F. Muntean, L.D. Bobos, M. TomoaiaCotisel, Particulate Science and Technology, 2016, 34 (5), 580.

13. G.A. Paltinean, I. Petean, G. Arghir, D.F. Muntean, M. Tomoaia-Cotisel, Revista de chimie (Bucharest), 2016, 67 (6), 1118.

14. W.C. Lo, R.H. Shie, C.C. Chan, H.H. Lin, Journal of the Formosan Medical Association, 2017, 116, 32.

15. Q. Xu, S. Wang, Y. Guo, C. Wang, F. Huang, X. Li, Q. Gao, L. Wu, L. Tao, J. Guo, W. Wang, X. Guo, Environmental Pollution, 2017, 220, 317.

16. M. Watanabe, H. Noma, J. Kurai, H. Sano, D. Hantan, M. Ueki, H. Kitano, E. Shimizu, Allergology International, 2017, 66, 52.

17. G.A. Paltinean, I. Petean, G. Arghir, D.F. Muntean, L. Muresan, M. TomoaiaCotisel, Annals of the Academy of Romanian Scientists Series on Physics and Chemistry Sciences, 2017, 2 (2), 43.

18. O. Horovitz, G. Tomoaia, A. Mocanu, T. Yupsanis, M. Tomoaia-Cotisel, Gold Bulletin, 2007, 40 (4), 295.

19. M. Tomoaia-Cotisel, A. Tomoaia-Cotisel, T. Yupsanis, G. Tomoaia, I. Balea, A. Mocanu, Cs. Racz, Revue Roumaine de Chimie, 2006, 51 (12),1181.

20. M.A. Naghiu, M. Gorea, E. Mutch, F. Kristaly, M. Tomoaia-Cotisel, Journal of Material Science and Technology, 2013, 29 (7), 628.

21. G. Tomoaia, O. Soritau, M. Tomoaia-Cotisel, L.-B. Pop, A. Pop, A. Mocanu, O. Horovitz, L.D. Bobos, Powder Technology, 2013, 238, 99.

22. G. Tomoaia, O. Horovitz, A. Mocanu, A. Nita, A. Avram, C.P. Racz, O. Soritau, M. Cenariu, M. Tomoaia-Cotisel, Colloids and Surfaces B: Biointerfaces, 2015, $135,726$.

23. P.T. Frangopol. D.A. Cadenhead, G. Tomoaia, A. Mocanu, M. Tomoaia-Cotisel, Revue Roumaine de Chimie, 2015, 60 (2-3), 265.

24. I. Petean, G. Arghir, M. Tomoaia-Cotisel, O. Horovitz, D.A. Pop, Journal of Optoelectronics and Advanced Materials, 2010, 12 (10), 2119. 
25. R.D. Pasca, G. Tomoaia, A. Mocanu, I. Petean, G.A. Paltinean, O. Soritau, M. Tomoaia-Cotisel, Studia Univ. Babes-Bolyai, Chemia, 2015, 60 (3), 257.

26. R.D. Pasca, A. Mocanu, S.C. Cobzac, I. Petean, O. Horovitz, M. Tomoaia-Cotisel, Particulate Science and Technology, 2014, 32 (2), 131.

27. G. Tomoaia, M. Tomoaia-Cotisel, L.B. Pop, A. Pop, O. Horovitz, A. Mocanu, N. Jumate, L.D. Bobos, Revue Roumaine de Chimie, 2011, 56, 1039.

28. M. Tomoaia-Cotisel, A. Mocanu, Revista de Chimie (Bucharest), 2008, 59 (11), 1230.

29. G. Furtos, M.A. Naghiu, H. Declercq, M. Gorea, C. Prejmerean, O. Pana, M. Tomoaia-Cotisel, Journal of Biomedical Materials Research Part B. Applied Biomaterials, 2015, 104 (7), 1290.

30. F. Goga, E. Forizs, A. Avram, A. Rotaru, A. Lucian, I. Petean, A. Mocanu, M. Tomoaia-Cotisel, Revista de Chimie (Bucharest), 2017, 68 (6), 1193.

31. I. Cojocaru, A. Tomoaia-Cotisel, A. Mocanu, T. Yupsanis, M. Tomoaia-Cotisel, Revista de Chimie (Bucharest), 2017, 68 (7), 1470.

32. O. Cadar, P.T. Frangopol, G. Tomoaia, D. Oltean, G.A. Paltinean, A. Mocanu, O. Horovitz, M. Tomoaia-Cotisel, Studia Univ. Babes-Bolyai, Chemia, 2017, 62 (4), Tom I, 67.

33. I. Petean, G. Tomoaia, O. Horovitz, A. Mocanu, M. Tomoaia-Cotisel, Journal of Optoelectronics and Advanced Materials, 2008, 10 (9), 2289.

34. G. Tomoaia, A. Mocanu, L.D. Bobos, L.B. Pop, O. Horovitz, M. Tomoaia-Cotisel, Studia Univ. Babes-Bolyai, Chemia, 2015, 60 (3), 265.

35. G. Tomoaia, M. Tomoaia-Cotisel, A. Mocanu, O. Horovitz, L.D. Bobos, M. Crisan, I. Petean, Journal of Optoelectronics and Advanced Materials, 2008, 10 (4), 961.

36. A. Mocanu, R.D. Pasca, G. Tomoaia, C. Garbo, P.T. Frangopol, O. Horovitz, M. Tomoaia-Cotisel, International Journal of Nanomedicine, 2013, 8, 3867.

37. G. Tomoaia, P.T. Frangopol, O. Horovitz, L.D. Bobos, A. Mocanu, M. TomoaiaCotisel, Journal of Nanoscience and Nanotechnology, 2011, 11 (9), 7762.

38. G. Tomoaia, L.B. Pop, I. Petean, M. Tomoaia-Cotisel, Materiale Plastice, 2012, 49 (1), 48. 